\title{
Sonoridades africanas en Iberoamérica: La marimba tradicional afroesmeraldeña, Ecuador
}

\author{
African Sonorities in Iberian America: \\ The Traditional Afro-Esmeraldan Marimba from Ecuador
}

Los instrumentos musicales reflejan, tanto en sus sonoridades como en sus materiales de construcción y disposición fisica, un proceso histórico social y una realidad cultural determinados; constituyen ámbitos de lectura de las distintas culturas en las que se insertan. El presente artículo aborda desde el contexto sociocultural, histórico y organológico el instrumento musical representativo de la cultura afrodescendiente del litoral pacífico del norte de Ecuador, la marimba. Transita por sus orígenes, materiales y técnicas de construcción, así como por sus características musicales representativas. La población afrodescendiente de la provincia de Esmeraldas, conformada progresivamente desde la diáspora afroamericana hasta nuestros días, constituye a la marimba como un ícono de su cultura, un cálido timbre que la representa.

Palabras clave: marimba, sonoridad, afrodescendiente, diáspora, Esmeraldas, Ecuador, África, Iberoamérica.

Musical instruments reflect a social-historical process and a specific cultural reality in their sonorities, the materials from which they were built and their physical layout. They serve as vehicles for interpreting the different cultures of which they form part. This article examines the socio-cultural, historical and organological context of the musical instrument representative of Afro-descendant culture from the Pacific coast of the north of Ecuador: the marimba. It looks at its origins, materials and construction techniques, as well as its representative musical characteristics. The Afro-descendant population of the province of Esmeraldas, created progressively from the Afro-American diaspora to the present day, adopted the marimba as an icon of its culture, a warm timbre that represents it.

Keywords: marimba, sonority, Afro-descendant, diaspora, Esmeraldas, Ecuador, Africa, Iberian America.

La llegada, asentamiento y desarrollo del grupo afrodescendiente en territorio esmeraldeño se produjo de manera paulatina en distintos momentos y coyunturas históricas. Esta singularidad, unida a la característica de que la mayor parte de la población afroesmeraldeña es fruto de migraciones africanas secundarias o terciarias en el continente americano, devino en la diversidad de orígenes africanos de los afroesmeraldeños que hoy día habitan la provincia.

Si bien es cierto que la cultura afroesmeraldeña mantiene determinados rasgos comunes a otras culturas afroamericanas, sin embargo presenta aspectos peculiares y genuinos, fruto de su propio proceso de conformación cultural $^{1}$. El pueblo afroesmeraldeño ha logrado definirse a través de las adversidades históricas, consolidándose como un grupo preciso y caracterís- 
tico, donde la música tradicional ha jugado un papel fundamental. Esta, a pesar de haber corrido el riesgo de desparecer debido a las prohibiciones históricas -gubernamentales y eclesiásticas- de su interpretación ${ }^{2}$, se ha mantenido en la población a través de los siglos.

El ámbito religioso es, con probabilidad, el que ha contribuido, en mayor medida, a la vigencia y perdurabilidad tanto del repertorio musical afroesmeraldeño como de la mayor parte de los instrumentos musicales que integran el conjunto tradicional, debido, principalmente, a la invariabilidad formal de las ceremonias en las que se desarrolla.

La población afroesmeraldeña es esencialmente religiosa y espiritual. Hoy día el catolicismo es la doctrina que impera en este grupo cultural y, tanto en las comunidades rurales como en los centros urbanos, la afluencia a las celebraciones que establece el calendario litúrgico es masiva. Por otro lado, el carácter espiritual de este grupo cultural no solo se expresa a través de la religión instituida, sino que su simbología y cosmovisión peculiares aportan datos fundamentales en su comprensión.

Los instrumentos musicales tradicionales afroesmeraldeños son portadores de una carga simbólica definitiva para el grupo cultural al que pertenecen. Dignos de respeto y atención de parte de la comunidad, es creencia popular afroesmeraldeña que los instrumentos musicales poseen un espíritu, que cobra vida en manos del intérprete y que afecta a quien lo escucha; un espíritu necesario para el colectivo comunitario afroesmeraldeño. Por ello, en ocasiones, cuando se inicia una fiesta tradicional, se vierte un poco de licor sobre las teclas de la marimba, para compartir con ella lo mismo que con el resto de la comunidad; este acto cubre una necesidad práctica, según asegura el antropólogo Norman Whitten:

Una de las respondedoras, o la señora de la casa, echa aguardiente al teclado de la marimba -acompañada por gritos femeninos de placer- aaaeeeiii, está tomando la marimba. Este último gesto es necesario para la última afinación del instrumento. Las duras teclas negras fabricadas de la palmera chontaduro, sueltan aceite cuando las golpean, y las 'secan' al echarle trago a la marimba, para así facilitar el toque más acertado con los porros de cabeza de goma ${ }^{3}$.

El conjunto instrumental tradicional afroesmeraldeño está compuesto por la voz -para el canto y la recitación-, el bombo, los cununos, el guasá,

\footnotetext{
${ }^{1}$ Juan Pablo Pezzi: "Aporte hacia la consolidación de la identidad del negro esmeraldeño: ¿Es el negro esmeraldeño un afroamericano?", Identidades en Construcción, Juan Pablo Pezzi et al. (eds.), Quito, Abya-Yala, 1996 pp. 11-98; Heidi Carolyn Feldman: Ritmos negros del Perú: reconstruyendo la herencia musical africana. Lima, Instituto de Estudios Peruanos, 2009; Wong Cruz, Ketty: La música nacional: identidad, mestizaje y migración en el Ecuador, Quito, Casa de la Cultura Ecuatoriana Benjamín Carrión, 2013.

2 Nina Friedemann: "Huellas de africanía en Colombia", Thesaurus, XLVII, 3, 1992, pp. 543-560.

${ }^{3}$ Norman E. Whitten: Pioneros negros. La cultura afro-latinoamericana del Ecuador y de Colombia, Quito, Centro Cultural Afro-Ecuatoriano, 1992, p. 128.
} 
las maracas y la marimba ${ }^{4}$. Exceptuando la voz, todos los instrumentos son de percusión ${ }^{5}$, lo que denota el fuerte carácter rítmico que impregna la música tradicional ${ }^{6}$.

La música se ejecuta, en el ámbito festivo, cuando el conjunto instrumental se presenta completo, con la marimba y la danza ${ }^{7}$; y en el ámbito religioso, cuando los membranófonos acompañan a las voces para el canto y la recitación, sin baile ni marimba.

La música tradicional afroesmeraldeña inscrita en el ámbito festivo presenta determinadas características organológicas, formales y musicales que la distinguen de su relativo contexto religioso ${ }^{8}$. En el entorno festivo la ma-

\footnotetext{
${ }^{4}$ Algunos autores afirman que, antiguamente, también se interpretaba el redoblante, instrumento de procedencia europea pero, en este caso, construido con materiales autóctonos de la zona y que se empleaba a modo de aviso para congregar a la comunidad. Cfr. Juan García Salazar: "Instrumentos musicales asociados a ritos afro-ecuatorianos en la zona norte de Esmeraldas", Opus, Revista de la musicoteca del Banco Central del Ecuador, 36, 1989, pp.57-63. Sin embargo, en la actualidad no existen vestigios del uso del redoblante. En la región del Chocó, en el Pacífico Norte colombiano, la población afrodescendiente mantiene este instrumento como esencial en su conjunto organológico para interpretar la música llamada de chirimías.

${ }^{5} \mathrm{Al}$ parecer, hubo una época en que la guitarra formaba parte de la organología tradicional afrodescendiente del Pacífico Sur colombiano (tan cercana y parecida a la afroesmeraldeña como se comentó). Según Álex Duque, percusionista, compositor y docente en el conservatorio de Cali, en Tumaco se utilizan guitarras en el currulao, debido a la influencia de los tríos musicales (dos guitarras y requinto) en la zona. Entrevista realizada por Fernando Palacios a Álex Duque, Cali, Colombia, 2013. Faustina Orobio, compositora, cantadora y docente de Guapi (Colombia), comenta que se usaban mucho las guitarras antiguamente en los bailes tradicionales, aunque no se mezclaba con la marimba, sino se mezclaba con timba (timbales) y con botellas de aguardiente raspadas como güiro. Entrevista realizada por Fernando Palacios a Faustina Orobio, Guapi Colombia, 2013. Por otro lado, llegó a Ecuador tanto la vihuela como la música escrita para este instrumento. Sin embargo, y pese a que la región Sierra del país establece la guitarra como instrumento principal, no se asentó en la costa esmeraldeña. El grupo cultural afrochoteño, población afrodescendiente situada en el callejón interandino ecuatoriano, sí emplea la guitarra como instrumento representativo de su cultura, probablemente debido a la interacción con los grupos culturales cercanos a su territorio de asentamiento.

${ }^{6} \mathrm{Al}$ igual que en las manifestaciones musicales africanas, como ya comentamos. Por otro lado, el etnomusicólogo Fernando Ortiz explica así el predominante uso de instrumentos de percusión: "su cultura le dio los instrumentos musicales que necesitaban en aquel ambiente cálido, abierto, de sabana y de selva, para que la tribu realizara sus funciones colectivas; así como en los países fríos y de hogares cerrados los individuos requirieron instrumentos más apropiados, de cuerda o de viento, para sus soliloquios líricos, de menor intensidad sonora pero de tonos más variados, de más armónicas resonancias y de menos posibilidades rítmicas". F. Ortiz: Los bailes y el teatro de los negros en el folklore de Cuba, Ciudad de la Habana, Letras Cubanas, 1981, p. 127.

${ }^{7}$ De igual manera ocurre en las culturas subsaharianas donde, explica el etnomusicólogo A. M. Jones "If the drums are beating but there is no singing or dancing Africans will think there is nothing happening. So too, if there is music, and the performers really mean business it is essential to have the full ensemble. This consists of the instruments of the orchestra, the hand-clap ping, the song, and the dance. All these four ingredients combine to form the central act of African music-making. A. M. Jones: "Indonesia and Africa: the Xylophone as a Culture-Indicator", The Journal of the Royal Anthropological Institute of Great Britain and Ireland, 89, 1959, pp. 155-168.

${ }^{8}$ Hoy día se conoce en la región pacífica sur colombiana como currulao a lo que se ha denominado aquí como música festiva; es decir, todo el repertorio musical tradicional que no se inscribe en el ámbito religioso. Por otra parte, algunos investigadores emplearon, en las décadas de los sesenta y setenta del siglo XX, este término para referirse al contexto festivo en la zona de Esmeraldas (N. E. Whitten: Pio-
} 
rimba adquiere un papel protagónico fundamentalmente tímbrico, melódico y polifónico. De hecho, algunos músicos e investigadores concuerdan en determinar nominalmente a la música desarrollada en este ámbito como toques de marimba o música para baile de marimba ${ }^{9}$. El baile se encuentra presente, invariablemente, siendo la unión de este y la música que le acompaña la estructura que completa el desarrollo del conjunto. Además, en este contexto, los hombres también se expresan mediante la voz para el canto, lo que no ocurre con frecuencia en el religioso.

Tradicionalmente, la música festiva afroesmeraldeña se realizaba en las llamadas casas de marimba ${ }^{10}$, espacios amplios, pertenecientes a particulares y ubicados, por lo general, en las riberas de los ríos, con el fin de que se pudiese oír, desde largas distancias, la música interpretada en ese espacio ${ }^{11}$. La cantadora afroesmeraldeña Rosa Huila12 comenta que "algunas personas hacían sus casas grandes, con bastante espacio para que la gente bailara ahí, para bailar la marimba". El marimbista afroesmeraldeño Papá Roncón ${ }^{13}$ cuenta que "La casa de la marimba casi siempre estaba a la orilla del río, para que el sonido de la marimba camine por encima del agua y llegue hasta el último pueblo, llamando y convocando a toda su gente [...] estos bailes solían durar varios días".

Por su parte Whitten ${ }^{14}$ relata que, en la década de los sesenta, cuando realizó su investigación, "cada caserío de 200 o más habitantes tiene una casa de la marimba, y cada pueblo tiene 2 (o más) marimbas, ubicadas tanto en los barrios más antiguos de la comunidad como en los recién formados. En el nicho de las moradas rurales, y dispersas, normalmente hay una casa de la marimba, ubicada de 4 a 6 horas de viaje en canoa".

Hoy día, las casas de marimba apenas se encuentran activas. Quizás el boom bananero de los cincuenta y la subsecuente introducción de aparatos de reproducción eléctricos así como la afluencia de población foránea hizo que otros contextos sociales de dispersión -como la cantina o el salón-

neros negros...) ya que, al parecer, esta designación era usual entonces entre la población afroesmeraldeña de la región norte de la provincia. Sin embargo, en la actualidad, no se habla de currulao en este sector, habiéndose establecido el término, expresamente, en el territorio colombiano y designando aquí a cada pieza musical con su nombre característico.

9 Pablo Guerrero: Enciclopedia de la música ecuatoriana, Quito, Corporación Musicológica Ecuatoriana, tomo II, 2004-2005, falta pp.

${ }^{10}$ El investigador estadounidense Jonathan Ritter nombra en su trabajo también como "cabildos" a las casa de marimba. J. Ritter: "Hibridez, raza y la marimba esmeraldeña: repensando las fusiones musicales en el pacífico negro ecuatoriano”, Ensayos. Historia y Teoría del arte, 18, 2010, pp. 98-121.

${ }^{11}$ El constructor de instrumentos y marimbista afroesmeraldeño Nacho Caicedo lo recuerda así: "Venía subiendo o bajando por el río y iqué lindo!, se escuchaba la marimba por el río." "no había motor todo era a remo" (Nacho Caicedo, 2014).

12 Entrevista realizada por Fernando Palacios a Rosa Huila, Esmeraldas (Ecuador), 2015.

${ }^{13}$ Juan García Salazar,: Papá Roncón: historia de una vida, Quito, Abya-Yala, 2011, p. 131.

14 N. E. Whitten: Pioneros negros..., p. 124. 
fuesen desplazando a los tradicionales ${ }^{15}$. Además, las recurrentes prohibiciones que la música del conjunto de marimba sufrió a lo largo de la década de 1940 hasta la de 1960, también contribuyó a que este repertorio, y por ende sus espacios de difusión, se mantuvieran vigentes con cierta fragilidad.

En la actualidad son los festivales musicales y los teatros los contextos que, generalmente, establecen la plataforma de presentación y difusión de la música festiva tradicional afroesmeraldeña, y donde esta se expresa sujeta a los cambios y variaciones que los nuevos escenarios precisan. Muchos músicos que partieron de la tradición, desde el punto de vista formativo, interpretan las piezas del repertorio en base a arreglos establecidos desde la estructura y la música, integrando elementos modernos con componentes de fusión, tanto organológica como armónica, rítmica y melódicamente ${ }^{16}$.

\section{La marimba afroesmeraldeña ${ }^{17}$}

La marimba se posiciona como elemento simbólico de la cultura tradicional afroesmeraldeña debido a aspectos inscritos en diversos contextos. Por un lado, en el ámbito sonoro, donde las características musicales peculiares que presenta el instrumento -timbre cálido, dirección melódica y sostén polifónico- conglomeran al conjunto instrumental tradicional. Debido a estas características, la marimba servía tradicionalmente de referente sonoro para congregar a la comunidad (tanto a los habitantes del centro rural como a los navegantes del río) invitándoles al baile que se estaba celebrando o que próximamente se iba a celebrar, en las llamadas casas de marimba ${ }^{18}$.

Por otro lado, en lo que atañe al ámbito socio-histórico ya que, durante siglos, este instrumento ha mantenido la pugna por sostenerse vigente

15 E. Whitten Whitten: Pioneros negros... y Pablo Minda Batallas,: La marimba como patrimonio cultural inmaterial, Quito, Instituto Nacional de Patrimonio Cultural, 2014.

${ }^{16}$ Resultan ilustrativas las observaciones que el musicólogo Phillipe Bohlman presenta de las interpretaciones en festivales: "By choosing to perform at the festival, musicians juxtapose two seemingly contradictory tendencies. On one hand, the musicians accommodate the festival requirement that they perform in a way that resembles every other group. On the other hand, at the moment they succumb to the requirement of similarity, they must also affirm that their community is unique and culturally distinct from all others. The festival turns ethnic culture on its head, confusing similarity and difference". Philip V. Bohlman: "Ethnic North America", Excursions in World Music, Bruno Nettl et al. (eds.), New Jersey, Pearson Prentice Hall, 2004, p. 285.

${ }^{17}$ Idiófono de golpe directo con placas de percusión en juegos, número 111.222.2., según la clasificación de instrumentos musicales propuesta por Hornbostel y Sachs.

${ }^{18}$ La cantante y coreógrafa afroesmeraldeña Petita Palma comenta: "Mi abuelo tenía colgada la marimba en la casa y los bombos los cununos y el guasá. Él vivía un poco más debajo de Borbón, las Islas, le llamaban. Y allá tocaba la marimba, cuando estaba subiendo el agua, y se oía clarito acá”. Entrevista realizada por Fernando Palacios a Petita Palma, Esmeraldas, Ecuador, 2015. 


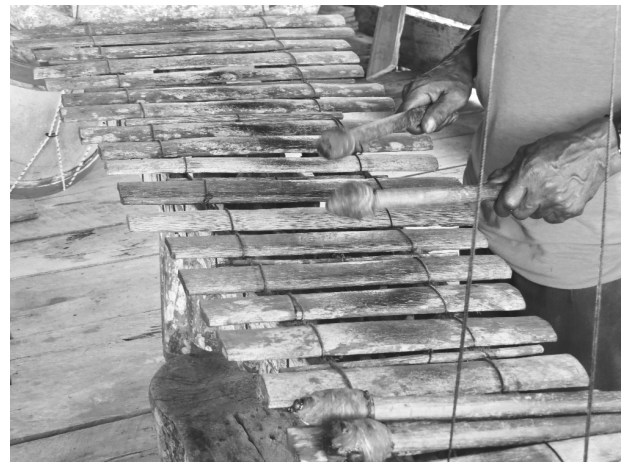

Ilustración 1. Marimba de familia Torres ${ }^{19}$

como representante de su cultura a pesar de la negación social sufrida por el pueblo afroesmeraldeño desde sus orígenes diaspóricos. La prohibición oficial de la interpretación de la marimba de parte de las autoridades locales, ocurrida en reiteradas ocasiones en la provincia de Esmeraldas, desde el siglo XVIII hasta el siglo $\mathrm{XX}$, donde se estigmatizaba al instrumento como antisocial y promovedor de un ámbito social contrario al decoro cívico, fue superada clandestinamente por la comunidad afroesmeraldeña, manteniéndose las interpretaciones aún a riesgo de ser sancionados. Hoy día se interpreta pública y libremente, con orgullo de pertenencia al pueblo afroesmeraldeño.

A pesar de que la voz es el elemento central de la tradición musical afroesmeraldeña, la marimba es la que organiza al conjunto instrumental, ejerciendo de núcleo sobre el que basculan el resto de instrumentos y la que, además, le dota del timbre cálido y armónico característico. Aunque es un instrumento de percusión, la disposición estructural en placas afinadas de agudos a graves la convierte en el elemento más versátil, en cuanto a melodía y polifonía, del conjunto.

La marimba afroesmeraldeña y sus correspondientes afrocolombiana, centroamericana e instrumentos de características similares pertenecientes a diversas culturas africanas, han sido reconocidos por la Unesco como $\mathrm{Pa}$ trimonio Cultural Intangible de la Humanidad debido a las características representativas fundamentales de las culturas a las que integran. A pesar de que recién en el año 2015 fue reconocida la marimba afroesmeraldeña como tal, ya desde el año 2003 formaba parte de la lista de bienes patrimoniales intangibles del territorio ecuatoriano.

\section{Origen $^{20}$}

La marimba tradicional afroesmeraldeña presenta rasgos constitutivos, tanto en sus componentes y materiales como en los aspectos melódicos, rít-

\footnotetext{
19 Todas las fotografías están tomadas por el autor.

20 Intentar establecer el origen determinado de un instrumento musical entraña el riesgo de perder de vista el entorno cultural donde actualmente se desenvuelve, al acrecentar la importancia de un pasado remoto; creemos que un intento de aproximación a tal fenómeno arrojará información útil en la comprensión tanto del instrumento en sí como del proceso histórico vivido por el pueblo al que representa. Confróntese al respecto la defensa del difusionismo como proceso cultural que establece el an-
} 
micos y polifónicos, que establecen nexos, en su origen, con instrumentos musicales afines pertenecientes a varias culturas subsaharianas del continente africano. Con el fin de conocer en mejor medida a la marimba afroesmeraldeña, revisaremos brevemente las tipologías principales y sus características generales fisicas y musicales de los instrumentos africanos.

\section{Tipologías de los xilófonos africanos}

En África se pueden distinguir tres tipos de xilófonos ${ }^{21}$, categorizados según su disposición física:

- El teclado de madera se dispone sobre un hueco cavado en la tierra o sobre un recipiente de arcilla, a su vez ubicado en un hueco cavado que funciona como caja de resonancia.

- El teclado se dispone sobre dos troncos de árbol de banano, sujetándose las teclas al tronco con pequeñas barras de madera que las separan. No dispone de resonadores.

- El teclado se dispone sobre un marco de madera debajo del cual se ubican unos resonadores de calabaza, acordes al tamaño de la tecla a la que dan resonancia; este instrumento puede estar colocado sobre un soporte o colgado con una soga natural rodeando la espalda del intérprete ${ }^{22}$.

Las tres tipologías se encuentran en diversos grupos culturales, desde la costa este a la costa oeste, de los actuales países del territorio subsahariano: Zimbabwe, Mozambique, Uganda, Kenya, Tanzania, Centro África, Camerún, Nigeria, Angola, Mali, Ghana, Burkina Faso o Senega ${ }^{23}$.

Sin embargo, los xilófonos africanos mantienen diversas denominaciones según su origen; amadinda en Uganda, balafón o gyil en Mali, Ghana y el Congo, timbila en Mozambique, igeri en Nigeria, baan en Burkina Faso o silimba en Zambia.

tropólogo Bronislaw Malinowski (Una teoría científica de la cultura, Madrid, Sarpe, 1984, p. 37), o el concepto de cluster cultural que el etnomusicólogo Alan. P. Merriam propone como método de estudio (The Anthropology of Music, Chicago, Northwestern University Press, 1964, p. 290).

${ }^{21}$ Genéricamente, xilófono se refiere a un instrumento con placas de madera afinadas según distintas alturas. La marimba pertenece a esta familia de instrumentos, al igual que, como veremos a continuación, sus homólogos subsaharianos. Estos, pese a ser muy parecidos, se nombran con otros términos y difieren en algunas de sus características constitutivas y musicales.

22 Este modelo es el que, con algunas variantes, se encuentra en Esmeraldas. F. Palacios Mateos: La riqueza de los instrumentos musicales tradicionales afroesmeraldeños: patrimonio cultural intangible, Quito, Abya-Yala, 2014.

${ }^{23}$ Arthur M. Jones: "Indonesia and Africa: the xylophone as a culture-Indicator", The Journal of the Royal Anthropological Institute of Great Britain and Ireland, 89, 1959, pp. 155-168; J. H. Nketia: The Music of Africa, Nueva York, W.W. Norton \& Company, 1974; Trevor Wiggins, J. Kobon: Xylophone Music from Ghana, Crown Point, White Cliffs Media Company, 1992; Thomas Turino: "The Music of Sub-Saharan Africa", Excursions in World Music, Bruno Nettl et al. (eds.), New Jersey, Pearson Prentice Hall, 2004, pp. 171-200; Emmanuel Nwachukwu Ndubuisi: The study of the 'Igeri' music of Amata autonomous community Ishiagu in Ivo local government area of Ebonyi state, tesis de máster, Nsukka, University of Nigeria, 2006 (inédita). 


\section{Características musicales de los xilófonos africanos}

El número de teclas varía de un instrumento a otro, desde 4 a 22 , y su afinación depende, por un lado, del grupo cultural en el que se inserta el instrumento y, por otro, del constructor que las elabore ya que, en ocasiones, dos constructores de un mismo grupo cultural disponen afinaciones distintas, al igual que ocurre en la cultura afroesmeraldeña. Sin embargo, en algunas culturas, como entre los Chopi de Mozambique, se interpretan los xilófonos en conjunto, con distintos instrumentos clasificados según el registro de las voces, llegando a integrarse hasta treinta de ellos al mismo tiempo, con un intérprete por cada xilófono; en este caso, la afinación de los instrumentos se realiza de tal manera que puedan interactuar entre sí.

Respecto a la ejecución, el número de intérpretes por instrumento se distingue según la cultura, desde un solo ejecutante -como los casos del balafón o la timbila - hasta seis, como ocurre en el reino de Buganda, actual Uganda, con el instrumento denominado amandinda. Dependiendo del grupo, para interpretar el instrumento el ejecutante puede estar sentado sin sostener el xilófono, de pie con el instrumento colgado al frente con ayuda de una cuerda que rodea su espalda, o sentado, sosteniendo al instrumento con sus piernas.

El ámbito melódico suele ser pentáfono, aunque no necesariamente establecido en alturas fijas tonométricas, a la manera occidental, sino basada cada afinación en su propio sistema interválico. Actualmente se encuentran algunas afinaciones cromáticas, con semitonos de distancias equidistantes, al igual que ocurre en la tradición afroesmeraldeña, lo que les permite interactuar con instrumentos temperados foráneos a su cultura de origen.

Los xilófonos africanos con resonadores de calabaza suelen tener una sonoridad característica, a manera de timbre nasal vibrante producido por el tipo de aceite empleado para recubrir el mismo y por una membrana hecha de tela del nido de araña, ubicada en el resonador y pegada con cera de abeja.

\section{Origen africano de la marimba afroesmeraldeña}

Como veremos a continuación, muchas de las características descritas en torno a los xilófonos subsaharianos se corresponden con las de la marimba afroesmeraldeña. Sin embargo, debido a la presencia de este tipo de instrumento en numerosas y dispares culturas del continente africano, se torna dificil establecer una procedencia africana, concreta, de la marimba afroesmeraldeña. Además, en territorio americano desarrolla características peculiares y propias. Podemos hallar una pista respecto al origen etimoló- 
gico del término marimba en el hecho de que, en la familia de lenguas Bantúes ${ }^{24}$, ma implica pluralidad y rimba una placa de madera sonora, es decir, un instrumento con gran número de placas de madera, lo que lleva a conjeturar la procedencia del instrumento afroesmeraldeño desde algunos de los países delimitados en el territorio donde esa familia lingüística se establece, manteniendo la misma denominación en el paso al continente americano ${ }^{25}$.

Algunos investigadores establecen el origen del xilófono africano en la región de Indonesia arguyendo que en el primer siglo a.n.e. se produjo un proceso de colonización de las costas de la isla de Madagascar por población procedente de la actual Indonesia, y que en él se introdujo el xilófono, característico de las orquestas musicales indonesias de gamelán ${ }^{26}$; este instrumento variaría en sus componentes y ejecución hasta devenir en los actuales xilófonos tradicionales africanos.

La marimba también se asentó, desde África, en otros territorios americanos distintos al afroesmeraldeño; tal es el caso de varias culturas centroamericanas situadas en México, Honduras o Guatemala ${ }^{27}$. De hecho, algunos teóricos aseguran que el origen de la marimba americana se encuentra precisamente en Centroamérica y no en África, basándose en lo hallado en algunas piezas cerámicas precolombinas, donde se observan instrumentos musicales de características parecidas al xilófono ${ }^{28}$. Sin embargo, es preciso constatar que instrumentos de placas percutidas existen desde hace muchos siglos en muy diversas culturas alrededor del mundo.

En Ecuador ya se encuentran litófonos ${ }^{29}$ en las culturas Guangala (500 a. n. e. al 500 d. n. e.), Bahía (600 a.n. e. al 600 d. n. e.) y Milagro Quevedo

${ }^{24}$ Diseminadas por los países que integran la región centro-sur, del continente africano.

${ }^{25}$ Cfr. Robert Garfías: "The marimba of Mexico and Central America", Latin American Music Review, IV, 2, 1983, pp. 14-49; Michael Williams: "Mbira/timbila, karimba/marimba: a Look at Some RelationsHips between African Mbira and Marimba", Scholarly Papers Presentation Session at Percussive Arts Society International Council, Indianapolis, 2000 (ponencia inédita); Max Johe Carreón: "La marimba", Conservatorianos, [s.n.], México, 2003, pp. 56-50.

26 A. M. Jones: "Indonesia and Africa: the Xylophone...; Adalberto Ortiz: "La marimba en América y Ecuador", Opus, Revista de la Musicoteca del Banco Central del Ecuador, 36, 1989, pp. 54-56; Charles Capwell: "The Music of Indonesia", Excursions in World Music, Bruno Nettl et al. (eds.), New Jersey, Pearson Prentice Hall, 2004, pp. 141-170.

${ }^{27}$ En la actualidad, se ha desarrollado en estos países hacia el ámbito orquestal, dando lugar a la denominada marimba sinfónica, para la que se han escrito diversas obras académicas, tanto solistas como de concierto (Paul Creston, Darius Milhaud o Robert Kurka). Para mayor información, Kathleen Kastner: The emergence and evolution of a generaliced marimba technique, tesis doctoral, Urbana, University of Illinois at Urbana-Champaign, 1989 (inédita).

28 Por ejemplo, el llamado "Vaso de Ratinlinxul", pieza Maya datada en el año 1000 d. n. e., donde aparece un personaje interpretando un instrumento de placas percutidas. M. J. Carreón: La marimba...

${ }^{29}$ Instrumento de placas de piedra pulidas y afinadas para ser percutidas. 
(500 a.n. e. al 1500 d. n. e.) ${ }^{30}$.A pesar de lo expuesto, generalmente se cree que la marimba centroamericana procede del continente africano y fue asimilada y modificada por las culturas que habitaban en esa región al llegar los colonizadores europeos ${ }^{31}$. Por otro lado es interesante constatar que la marimba tradicional centroamericana dispone, en los resonadores, de una membrana que modifica el timbre del instrumento hacia un carácter brillante y vibratorio, al igual que los descritos xilófonos africanos.

\section{Llegada de la marimba a Esmeraldas}

Como el resto de instrumentos del conjunto tradicional, la marimba procede de África y se instala en la región de Esmeraldas desde una doble aproximación histórico-geográfica: de un lado, por los primeros pobladores afrodescendientes, arribados a las costas esmeraldeñas en el siglo XVI, quienes reprodujeron, con los materiales que encontraron a su alcance, los instrumentos que traían en la memoria ${ }^{32}$; de otro, debido a que acompañó a la población afrodescendiente en su afluencia a las minas de oro del norte de la provincia desde el actual territorio del Pacífico Sur colombiano, a fines del siglo XVIII.

\section{Componentes del instrumento y sus materiales de construcción}

Trataremos, a continuación, tanto los componentes con los que se estructura la marimba como los materiales empleados para la fabricación de cada uno de ellos.

\section{Las tablas}

También llamadas teclas o notas, son las piezas que conforman el teclado ubicadas de menor a mayor tamaño.

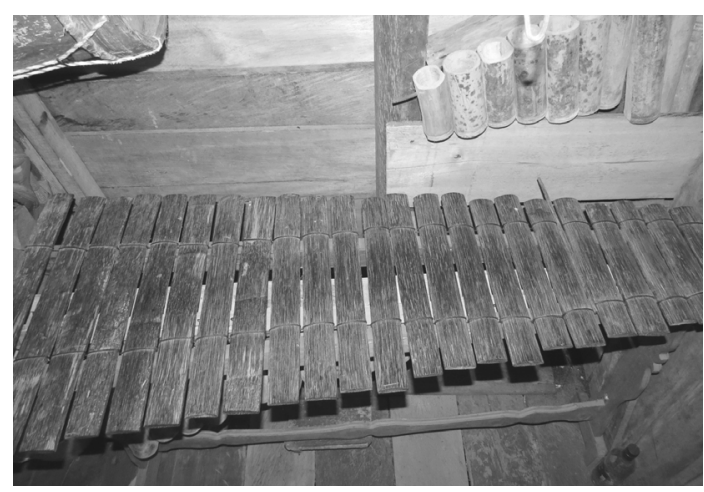

Ilustración 2. Tablas de marimba

30 Jaime Idrovo Urigüen: Instrumentos musicales prehispánicos del Ecuador, Cuenca, Banco Central del Ecuador, 1987; Byron Uzcátegui Andrade: "Prehistoria musical del Ecuador", Opus, Revista de la musicoteca del Banco Central del Ecuador, 33, 1989, pp. 10-29.

${ }^{31}$ R. Garfías: "The Marimba of Mexico..."; M. J. Carreón: La marimba...

32 Sin embargo, no existen datos fehacientes que establezcan, en estas fechas, la presencia del instrumento musical en la región. El primer testimonio hallado sobre la marimba en Esmeraldas data del año 1808, descrito por el investigador W. B. Stevenson, quien fuera en 1810 gobernador de la provincia. 

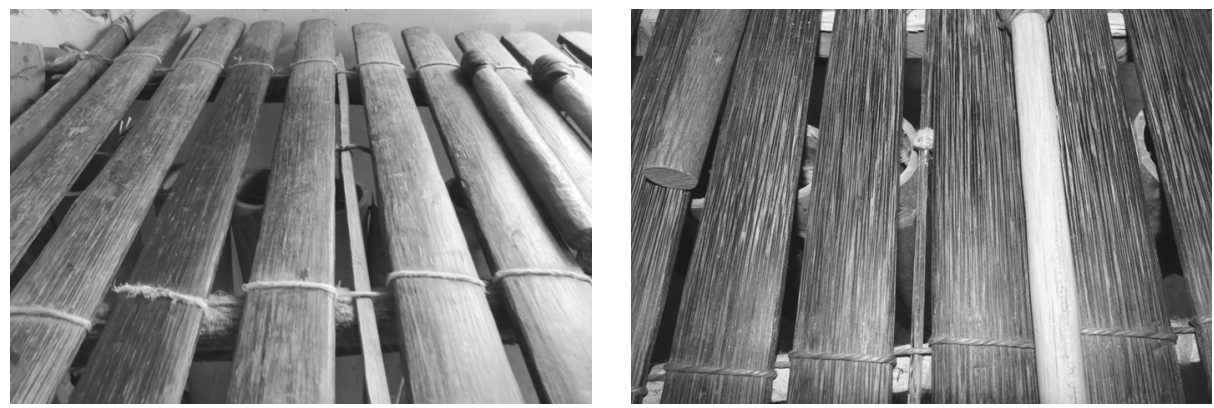

Ilustraciones 3 y 4. Cosido de tablas y Nylon para el cosido

Se construyen de madera de chonta, un tipo de palma cuyas características principales son la dureza y la resonancia.Aunque hay varias clases de chonta, no todas se emplean para la construcción del instrumento, siendo la llamada gualte la más adecuada, por sus propiedades fisicas, de gran resonancia y dureza. La madera de la parte más cercana a la raíz es la más apropiada para la construcción, por presentar mejor resonancia que la madera de la parte superior de la palma.

Las teclas se unen entre sí con una fibra natural denominada cosedera mediante un proceso conocido como cosido.

El constructor afroesmeraldeño Nacho Caicedo cuenta así el proceso de elaboración de tal fibra: "para conseguirla, hay un yarumo en el monte, hay muchos yarumos, pero para sacar esto es uno específico. Él se cría largo. Se raya abajo, se tiréa y se saca la corteza. Cuantas tiras le dé.Y ahí usted le saca lo de afuera, lo pela bien peladito y esto va bien masticado, de ahí se lava y se pone a secar y sale la cosedera. Se cose dándole vueltas" ${ }^{33}$. Actualmente muchos constructores sustituyen la cosedera por hilo de nylon.

\section{Los resonadores}

Conocidos como canutos, conforman las cajas de resonancia de las teclas a las que acompañan. Se disponen debajo del teclado correspondiendo en espacio y en tamaño uno a cada tabla. Se construyen de caña guadua, un material fácil de trabajar, con propiedades de resonancia adecuadas y que dispone en su interior de nudos naturales que la compartimentan. Los resonadores se presentan cerrados naturalmente, con el nudo de la caña en la parte inferior. 2014

33 Entrevista realizada por Fernando Palacios a Nacho Caicedo, Telembí, Esmeraldas (Ecuador), 

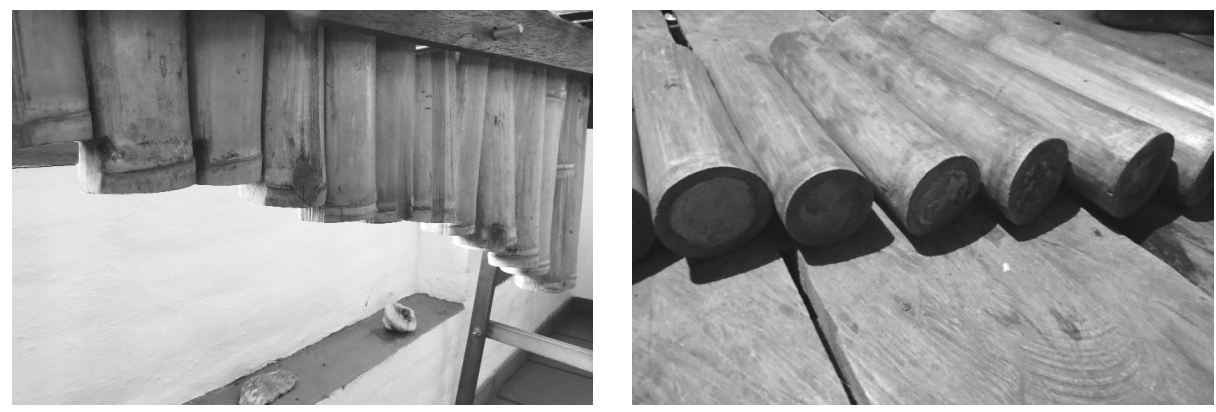

Ilustraciones 5 y 6. Resonadores de Marimba y Nudos naturales de resonadores
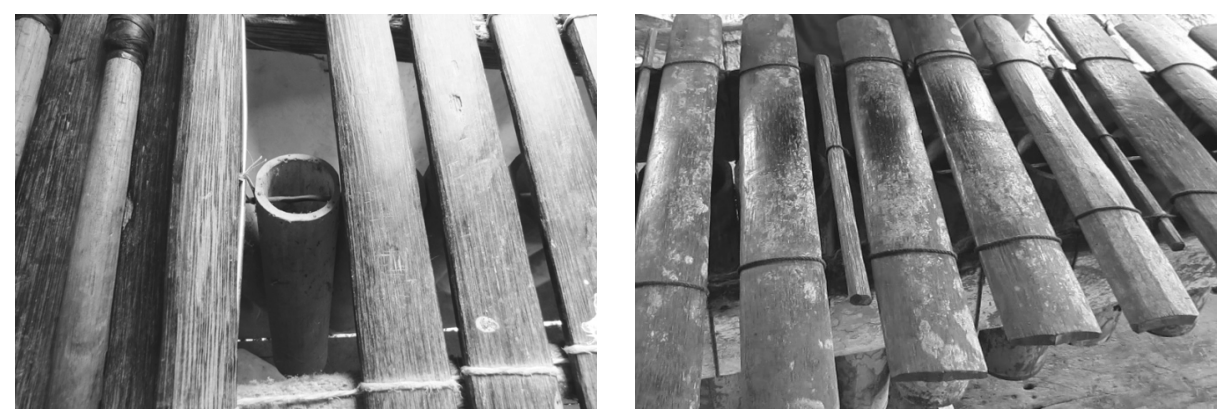

Ilustraciones 7 y 8. Baqueta y Pasadores

De igual manera a la chonta, existen diversos tipos de caña, siendo la apta más para los canutos la de menor grosor.

Una vara, tradicionalmente de chonta y actualmente de acero, denominada baqueta, atraviesa todos los resonadores en su parte superior para unirlos como una sola pieza y poder ubicarlos bajo sus correspondientes teclas.

Con el fin de sostener de manera estable los resonadores al teclado, se disponen pequeñas piezas de chonta, cada dos o tres tablas, bajo la baqueta en el centro y sobre la parte inferior del teclado en los laterales. Esta pieza se denomina pasador.

\section{Almohadillas}

Las tablas deben asentarse sobre una superficie lisa y esponjosa, de tal manera que, al ser percutidas, la resonancia se mantenga y propague en el tiempo. Esta base se denomina almohadilla y tradicionalmente consistía en una fibra natural trenzada llamada damagua o jicrilla, como vemos en la imagen anterior. Hoy día este material se ha sustituido por esponja sintética o goma de caucho. 

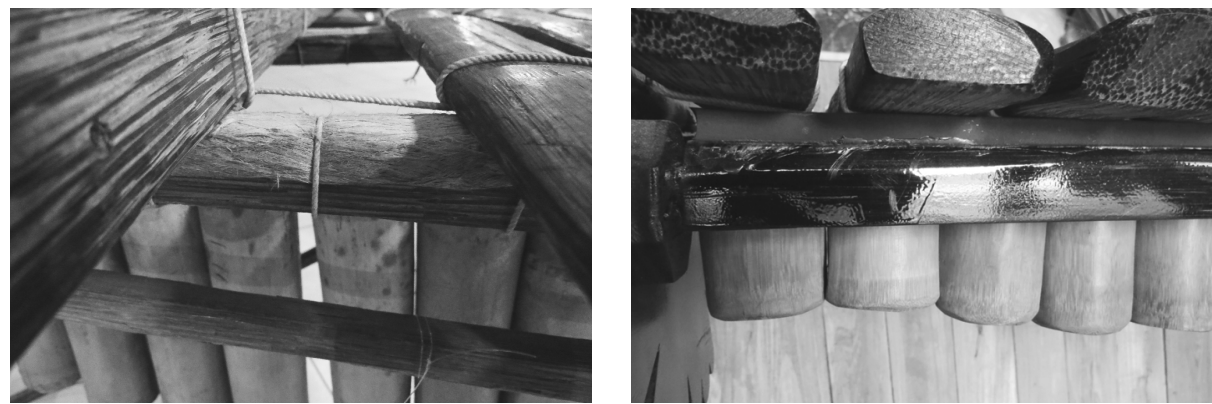

Ilustraciones 9 y 10. Almohadillas de Jicrilla y de goma

En ocasiones recubiertas de tela.

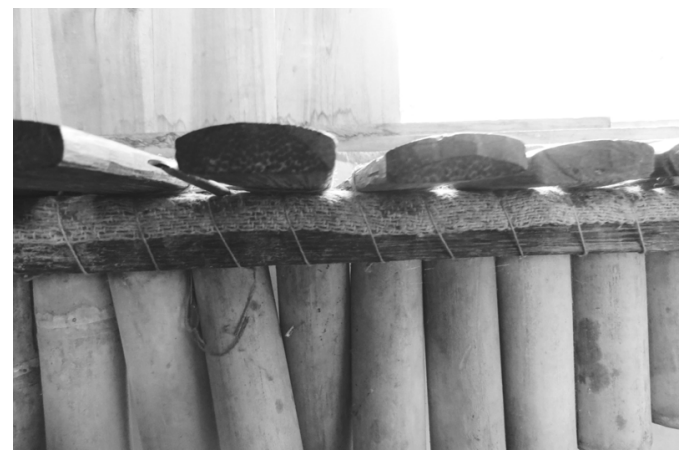

Ilustración 11. Almohadilla de goma recubierta de tela

\section{Marco}

Es la estructura sobre la que se asientan las almohadillas y, encima de estas, el teclado, al que se sostienen los resonadores. Tiene una forma trapezoidal que se estrecha en uno de sus lados, correspondiéndose su forma a la proporción en aumento del tamaño de las teclas.

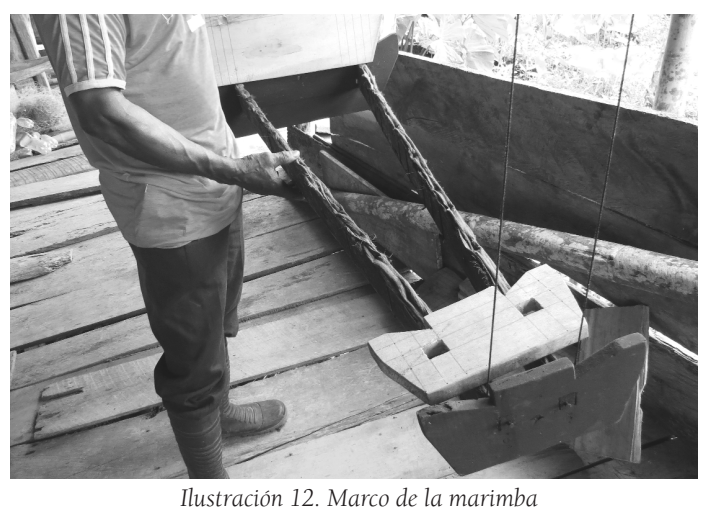


En ambos laterales se ubican dos piezas denominadas cabeceras, trabajadas en madera de cedro o guajarico.

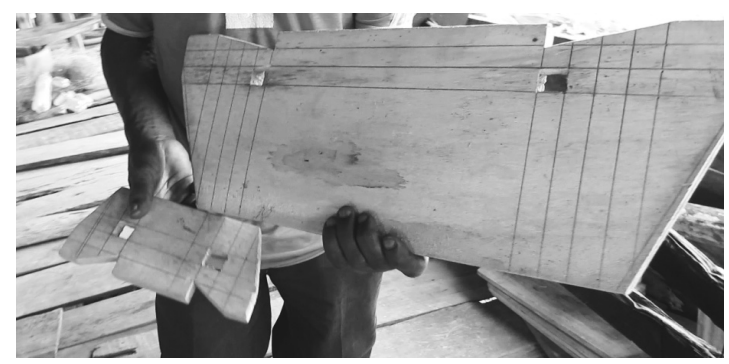

Ilustración 13. Cabeceras

Son las que unen los travesaños, denominados varones, realizados en madera de palealte o jiguanero.

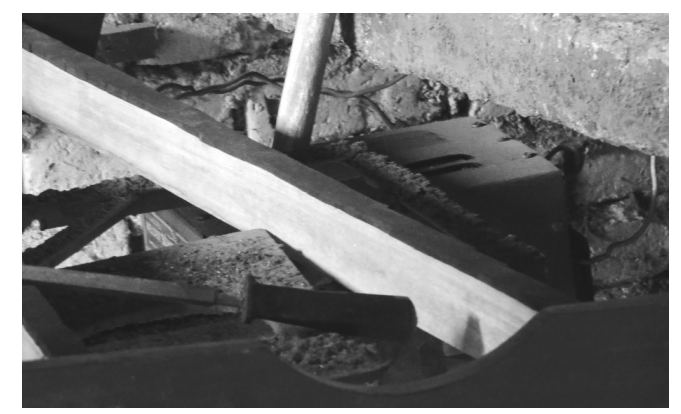

Ilustración 14. Varón

\section{Soporte}

Aunque la marimba tradicionalmente se interpreta colgada (o guindada) de las vigas de la casa donde se ubicaba mediante el uso de cuerdas fabricadas de fibras naturales, actualmente, por facilitar los traslados y la ubicación en espacios ajenos a su entorno habitual, se encuentra emplazada sobre un soporte a manera de caballete que se denomina burro y se construye del mismo tipo de madera empleado para el marco. Algunos cons-
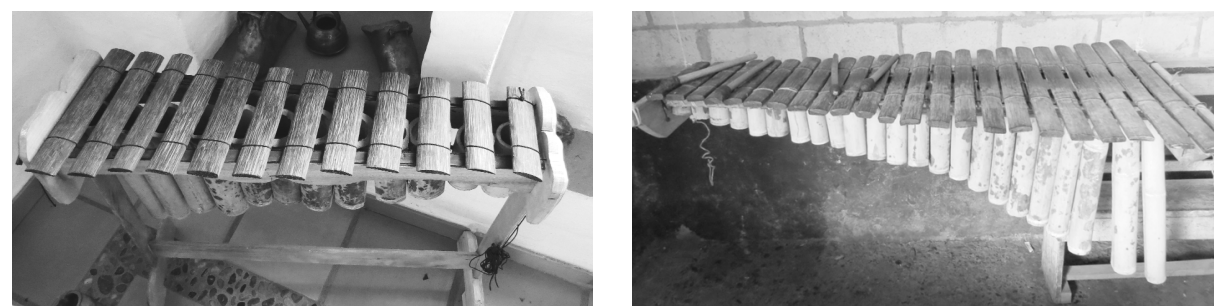

Ilustraciones 15 y 16. Soporte de marimba y Marimba guindada 
tructores, en el intento de permitir que la marimba siga colgada aún cuando se deba trasladar, han ideado un soporte de caña guadua que mantiene guindado al instrumento, sin embargo esta plataforma no ha resultado muy cómoda en el proceso de armado, por lo que apenas se emplea.

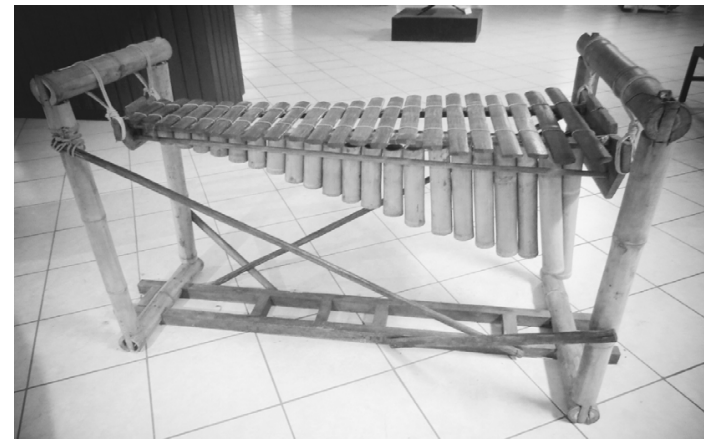

Ilustración 17. Soporte de caña guadua

\section{Tacos o mazos}

Son las baquetas empleadas por los intérpretes para percutir la tablas. Consisten en dos varas de mediano tamaño, cilíndricas y pulidas, que presentan en su extremo una esfera de caucho para que la baqueta rebote al percutir y permitir así que el sonido de la tabla no se apague. La madera empleada en su construcción es diversa: laurel, arce, chonta o tillo.

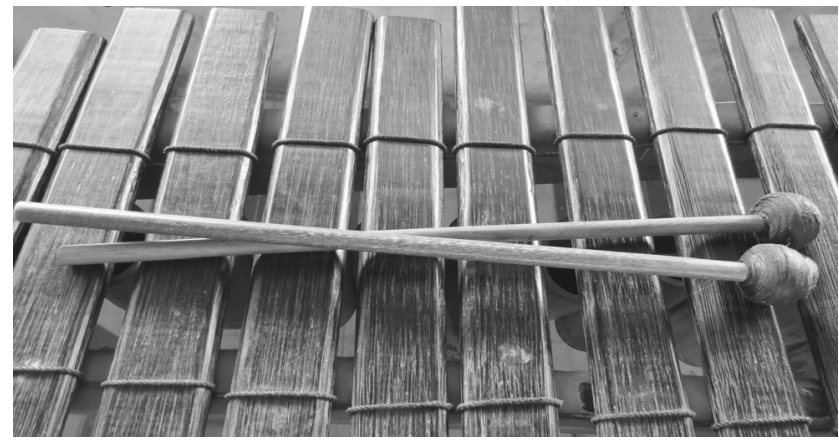

Ilustración 18. Tacos de marimba.

\section{Proceso de construcción}

Generalmente se construye, en primer lugar, el marco de la marimba en sus dos componentes: los varones ensamblados a las cabeceras; ya que esta pieza constituye el sostén del instrumento, a la que se adapta el resto.

Las cabeceras presentan un pequeño orifico por donde pasará la baqueta de los resonadores.

Posteriormente se adaptan las almohadillas a los varones, tradicionalmente enrollada la fibra natural a la madera o actualmente, adherida con pegamento industrial. Una vez adecuadas estas se asientan las tablas, dispuestas por tamaños de menor a mayor longitud y se cosen al marco, enlazando una tecla tras otra con la cosedera o con la cuerda de nylon. 

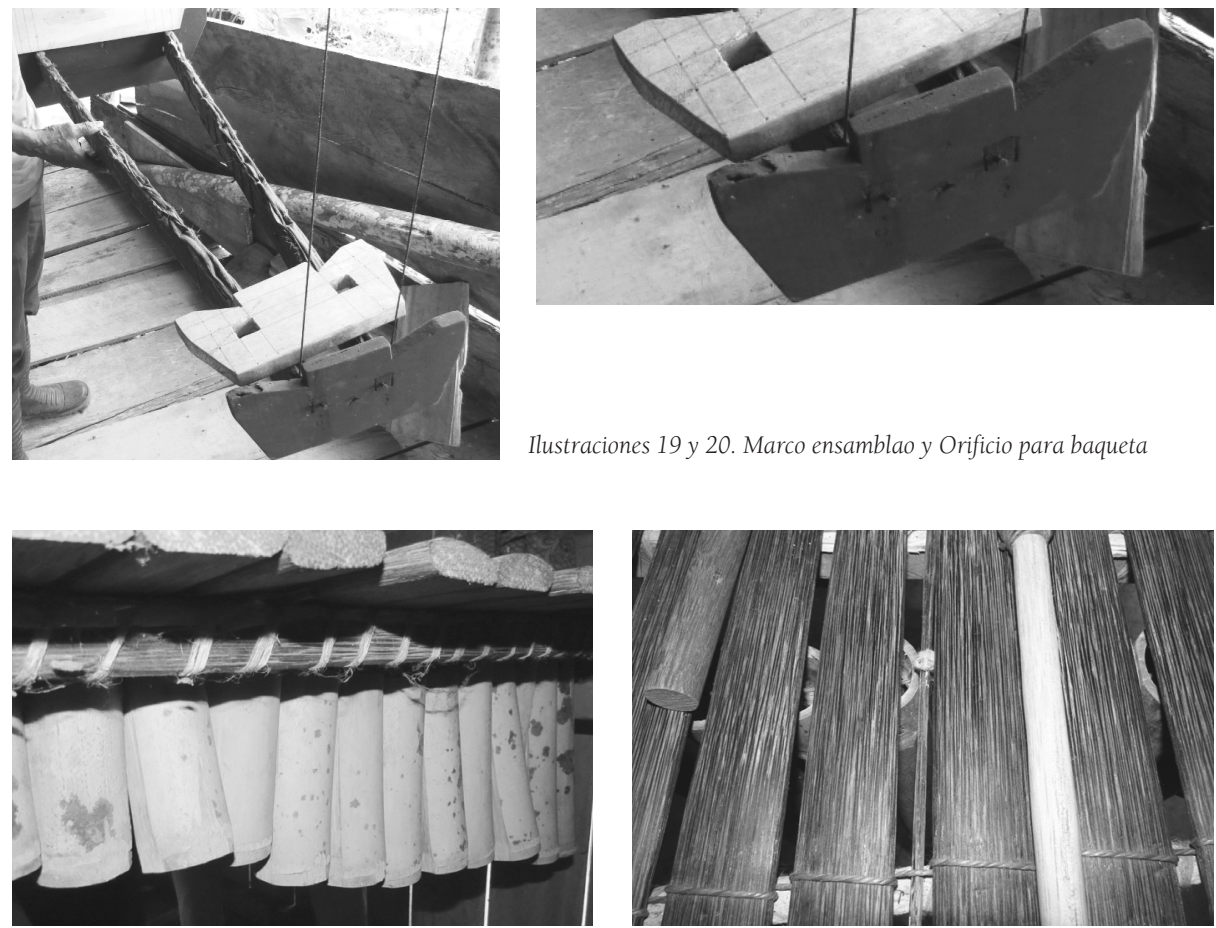

Ilustraciones 21 y 22. Unión de de almohadillas a los varones y Cosido de tablas

El también constructor afroesmeraldeño Alberto Castillo rescató una nueva técnica de cosido, ideada por el constructor afroesmeraldeño Numas Ramírez, mediante orificios realizados en cada tecla, para pasar por ellos la cuerda que las una pero, no satisfecho con el resultado, desechó esta técnica para seguir con la tradicional ${ }^{34}$.

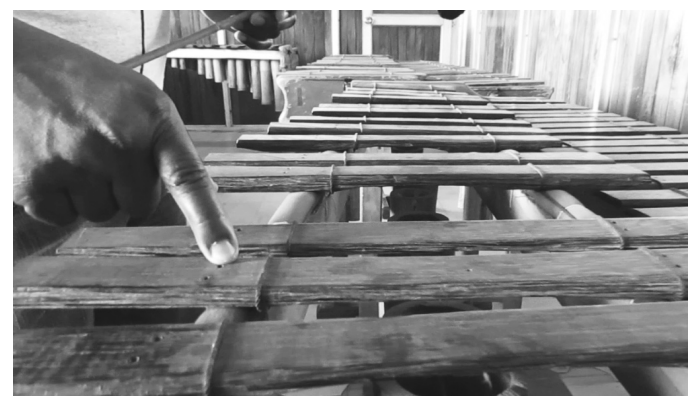

Ilustración 23. Técnica alternativa de cosido

34 Mireya Ramírez de Morejón: Folklore de la zona norte de Esmeraldas, Quito, Centro de Investigación y Cultura del Banco Central del Ecuador, 1984. 
Dispuestas las teclas, se procede a ubicar la baqueta con los resonadores bajo el teclado, haciendo coincidir cada canuto con su correspondiente tecla superior. La baqueta sale a cada lado de las cabeceras por el orifico referido donde se sujeta al otro lado de la misma, tradicionalmente, mediante técnica de amarre y, actualmente, con una tuerca en forma de mariposa.

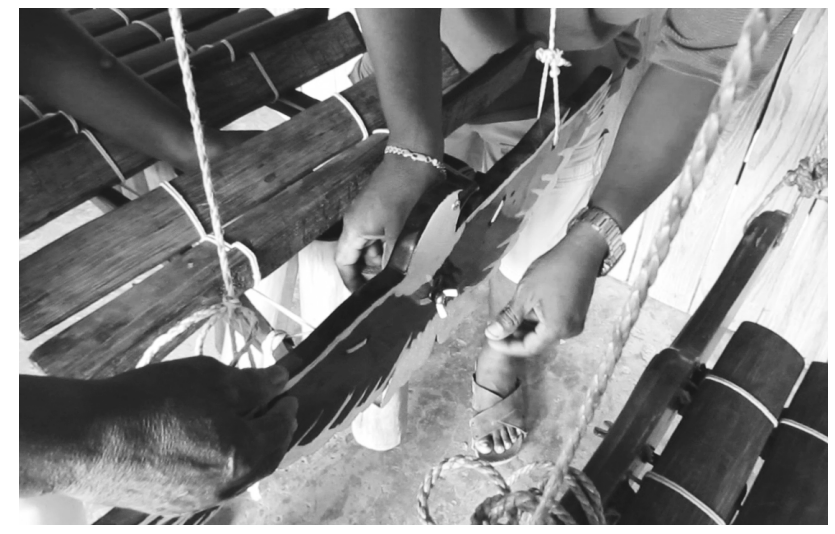

Ilustración 24. Cierre de baqueta

Por la especialidad que encierra el proceso individual de construcción de algunos componentes de la marimba creemos preciso describirlos:

Las tablas se desbastan con machete, lavándolas superficialmente para ser lijadas y pulidas en su fase final. Se trabajan desde la más pequeña hacia la más grande, hecho que encierra un significado simbólico fundamental: la relación cronológica de un ser vivo, desde su nacimiento a su muerte. El constructor afrocolombiano Pacho Torres comenta al respecto que:

¿no ves que cuando uno nace, nace tiraíto (sic) en el suelo?Y de ahí le cortan el ombligo, luego lo lavan, le curan el ombligo y lo meten adentro de la bateita o a la cunita.Y de ahí enprincípia (sic) uno a llorar, para que le den de comer.Y de ahí después emprincípia uno a sentarse.Y de ahí después emprincípia uno a gatear.Y de ahí vamos a caminar y conforme vamos caminando vamos creciendo; y así es el instrumento, uno nace chiquito ${ }^{35}$.

La afinación de las tablas se realiza con machete, raspando la parte central inferior de cada tecla hasta conseguir el sonido deseado por el constructor, siendo más agudo cuanto más material se extraiga ${ }^{36}$.

\footnotetext{
35 Entrevista realizada por Fernando Palacios a Pacho Torres, Guapi (Colombia), 2013.

36 Sin embargo, el constructor afroesmeraldeño Benjamín Vanegas, también ingeniero naval, ha desarrollado una fórmula matemática en donde, empleando las variables de longitud y ancho, el grosor de las teclas no varía en relación de una a otra. Entrevista realizada por Fernando Palacios a Benjamín Vanegas, Esmeraldas, Ecuador, 2015.
} 
Los resonadores deben estar pulidos en su parte externa y cortados cada uno a una longitud tal que mantengan la misma afinación que la tabla a la que corresponde, para ello se va tocando la tabla con el canuto ubicado debajo de la misma y se recorta el resonador, poco a poco, hasta que los armónicos de la tecla se ajusten a su correspondiente resonador ${ }^{37}$.

Algunos constructores emplean agua para realizar este proceso: introducen agua en el canuto y, de igual manera tocando la tabla correspondiente, van sacando agua hasta que el sonido de ambos se complemente; una vez establecida la resonancia resta cortar el canuto a una distancia igual a la que ocupa el agua que se encuentra en el interior ${ }^{38}$.

Los constructores tradicionales aseguran que es necesario poder interpretar la marimba para saber construirla. Cada constructor emplea un tiempo variable en la construcción del instrumento que puede variar de una semana a un mes. La marimba es un instrumento que, con los cuidados precisos, protegiéndola de la lluvia y el sol directo, puede llegar a durar mucho tiempo. El constructor afroesmeraldeño Nacho Caicedo asegura que la marimba de su padre duró ochenta años.

\section{Dimensiones}

Las medidas de la marimba dependen del número de tablas de que disponga el instrumento. Hay marimbas desde 8 hasta 24 teclas. Cada constructor mantiene su propia técnica y metodología para establecer las dimensiones genuinas de los instrumentos que elabore. El maestro afroesmeraldeño Nacho Caicedo dispone de una barra de madera, de medias determinadas previamente por él, que le ayuda a establecer el largo del instrumento, según el número de teclas. El constructor afrocolombiano Ado Obed establece mediante fórmulas matemáticas las dimensiones del instrumento, al igual que, como ya comentamos, determina el constructor afroesmeraldeño Benjamín Vanegas ${ }^{39}$.

\footnotetext{
${ }^{37}$ El constructor afrocolombiano Ado Obed numera en su parte inferior los canutos, una vez afinados, con el fin de facilitar el proceso de ensamblaje de estos en la baqueta. Entrevista realizada por Fernando Palacios a Addo Obed, Cali (Colombia), 2014.

${ }^{38}$ El etnomusicólogo Simah Arom relata que esta misma técnica se emplea para afinar los xilófonos en Camerún donde: "Para afinar estos instrumentos en Camerún se utiliza agua: cuando se desea subir el tono, se introduce agua en los tubos y si la altura resulta excesiva, se extrae líquido. El procedimiento es sumamente empírico. La afinación puede variar unos tres cuartos de tono". S. Arom: "El papel de la experimentación interactiva en el estudio de las músicas tradicionales de África central", Los últimos diez años de la investigación musical, Jesús Martín Galán y Carlos Villar-Taboada (coords.), Valladolid, Universidad de Valladolid, 2002, p. 133.

${ }^{39}$ En la actualidad algunos constructores basan algunas de sus medidas en aspectos tan prácticos como que la marimba pueda adecuarse al espacio del maletero de un automóvil, facilitando así su traslado. Es el caso del constructor afrocolombiano Ado Obed.
} 
Generalizando, cada tabla suele tener entre 5 y $6 \mathrm{~cm}$ de ancho por $1 \mathrm{~cm}$ de espesor, y la dimensión del largo va aumentando a razón aproximada de $1 \mathrm{~cm}$ por cada tabla dirigiéndose hacia el registro grave del instrumento, es decir, las teclas de mayor longitud. La altura del instrumento, cuando este se dispone sobre el soporte o burro, alcanza hasta un metro.

\section{Afinación}

Cada constructor tradicional mantiene una metodología y una disposición interválica propia en la afinación del instrumento. La distancia entre sonidos no se corresponde a la división tonométrica usual en el sistema temperado, sino que presenta peculiaridades, como comentamos, entre cada constructor, variando incluso de un instrumento a otro realizado por las mismas manos.

Veamos algunas de las metodologías que emplean los constructores para establecer las alturas de referencia sobre las que se afinan el resto de tablas:

El constructor e intérprete afroesmeraldeño Papá Roncón recita una oración católica que emplea como modelo tonal de referencia, buscando que las teclas de la marimba suenen igual al recitado:
Allá van las tres Marías, van por el monte calvario en busca del Redentor que van a crucificarlo.

Y comenta que "cuando la marimba me dice eso, está bien para afinar" Por su parte, el constructor afroesmeraldeño Remberto Escobar registraba el canto de un ave, llamada pájaro marimbero, como nota más aguda del instrumento, estableciendo el resto de notas en la búsqueda de la sonoridad característica de la pieza musical del repertorio festivo agua larga ${ }^{41}$.

Algunas afinaciones tradicionales presentan bastante similitud con el sistema diatónico temperado, abarcando, en ocasiones, octavas tonométricas ${ }^{42}$. Presentamos a continuación varios ejemplos de afinaciones que, aunque dispuestas en notación tradicional occidental, nos sirven como modelos referenciales, aproximados, de las mismas. Estos instrumentos pertenecen a los marimbistas Nacho Caicedo, papá Roncón y Pacho Torres respectivamente.

\footnotetext{
40 Entrevista realizada por Fernando Palacios a Guillermo Ayoví (Papá Roncón) en Borbón, Esmeraldas (Ecuador), 2014.

${ }^{41}$ Cfr. Remberto Escobar Quiñónez: Memoria viva: costumbres y tradiciones Esmeraldeñas, Quito, Distrito Metropolitano de Quito, 1997.

${ }^{42}$ El marimbista y constructor afroesmeraldeño Nacho Caicedo relata que, en una ocasión, de visita en la capital, le pidieron que interpretara alguna pieza al piano. Él, correspondiendo las notas de la marimba a las del piano, interpretó una de las piezas tradicionales afroesmeraldeñas en aquel instrumento temperado.
} 

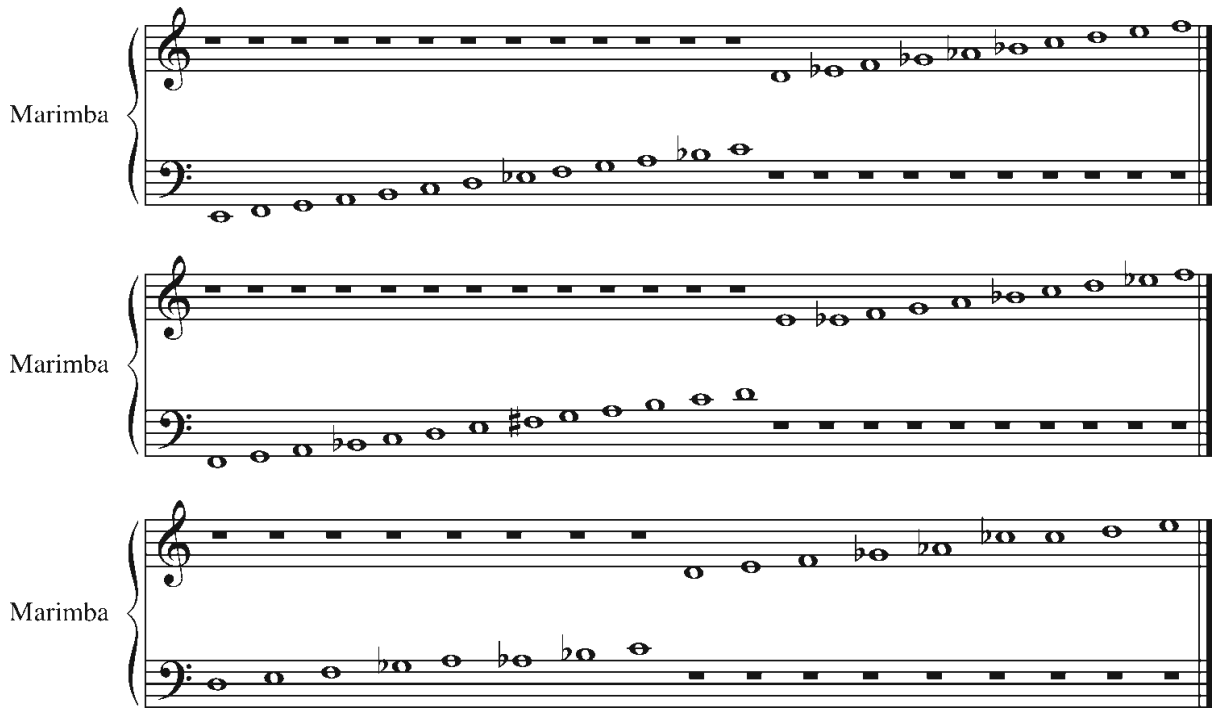

Ejemplo 1. Afinaciones marimbas afroesmeraldeñas

Los constructores tradicionales coinciden en que el entorno para la afinación debe ser propicio, en silencio y, si es posible, en noches de luna llena y con la marea a media vaciante ya que, según el constructor afroesmeraldeño Remberto Escobar: "Cuando esta sube [la marea] se afinca más el sonido obtenido durante la afinación" 43.

En la actualidad, el sistema temperado ha ganado terreno en las afinaciones de las marimbas, llegando casi a opacar al sistema tradicional. Los instrumentos así construidos se disponen o diatónicamente -abarcando una o dos octavas- o cromáticamente -abarcando un rango de dos octavas y media ${ }^{44}$, comenzando casi siempre desde un Fa grave $-{ }^{45}$.

\section{Técnicas de ejecución}

Los intérpretes de marimba se denominan marimberos. Tradicionalmente son dos: uno toca en el registro grave del instrumento -región conocida como bordón (denominado bordonero) - y otro en el registro agudo -ámbito sonoro llamado tiple o requinta (nombrado como requintero o

${ }^{43}$ R. Escobar Quiñónez: Memoria viva: costumbres..., p. 49.

${ }^{44}$ El constructor afroesmeraldeño Alberto Castillo comenta que si se realizan de más octavas los resonadores resultan muy grandes para sostenerse en el marco y mantenerse en buenas condiciones en el tiempo. Entrevista realizada por Fernando Palacios a Alberto Castillo, Esmeraldas, Ecuador, 2014.

${ }_{45} \mathrm{Al}$ parecer, en la cultura afroesmeraldeña el constructor Numas Ramírez, vecino de la localidad de San Lorenzo, al norte de la provincia, fue el primero en afinar las marimbas cromáticamente. Hoy día, los constructores Alberto Castillo y Benjamín Vanegas, continúan esta disposición temperada. 
tiplero ${ }^{46}$ - Cada una de estas regiones mantiene características melódicas y polifónicas peculiares, como veremos más adelante.

La disposición de ambos intérpretes varía, pudiendo establecerse de varias formas: uno junto al otro, en el mismo lado del instrumento; o un intérprete frente al otro, situados en lados opuestos del mismo.

Los marimberos tocan el instrumento de pie, erguidos pero no rígidos, utilizando los mazos o tacos anteriormente descritos, generalmente dos para cada intérprete, uno en cada mano ${ }^{47}$. Estos mazos se sostienen por su base, entre los dedos índice y pulgar y sujetándolo por la parte inferior con el resto de los dedos. El sonido se produce al percutirlos contra la parte central de las tablas y con la ayuda de la resonancia de los canutos para su amplificación. Los tacos no se separan apenas de las tablas al percutirlas.

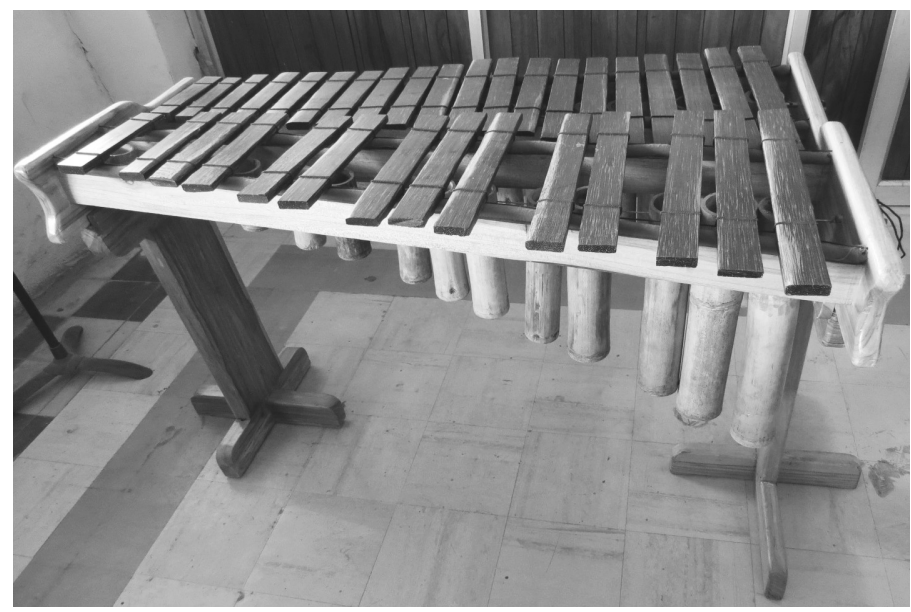

Ilustración 25. Marimba cromática

Actualmente la figura del bordonero va desapareciendo debido, por un lado, a la escasez de intérpretes y, por otro, a las nuevas disposiciones melódicas y armónicas implementadas tanto con la marimba cromática como por la interacción de esta en agrupaciones que unen géneros e instrumentos musicales foráneos a la cultura tradicional, de manera que suele ser un solo intérprete el que ejecuta el instrumento, intercalando los pasajes melódicos del bordón con los de la requinta, en detrimento de la riqueza

${ }^{46}$ El etnomusicólogo K. Nketia refiere que en algunas culturas africanas el xilòfono presenta estas mismas regiones sonoras: "Entre los Malinke, Chopi y Lobi, hay un patrón repetido con otro intérprete o con la mano derecha y una melodía con variaciones en la mano izquierda o con otro intérprete.". J. H. Nketia: The Music..., p. 123.

${ }^{47}$ La actual marimba sinfónica se ejecuta con dos tacos en cada mano del intérprete. Por ello, el marimbista colombiano Héctor Tascón, de formación académica, ha implementado esta disposición en la marimba tradicional, obteniendo, según su criterio, excelentes resultados. 
polifónica y polirítmica que se genera al contar con dos intérpretes. El constructor y marimbista afroesmeraldeño Papá Roncón (2014) comenta al respecto que: "La marimba siempre necesita de dos. Suena bien, pero cuando son dos músicos que la tocan. Uno solo no puede porque falta el complemento que es el bordón. Es como cuando usted se pone a tocar la guitarra y solo toca en prima. Ahí no escucha nada. Pero, cuando toca la cuarta, quinta y sexta, eso ya es otra cosa". El marimbista afrocolombiano Genaro Torres lo confirma: "El bordón siempre acompaña. Para cantar un bambuco bien cantao (sic) se necesita uno que bordonee, el de la requinta y el del bordón. Ahí sí haces un bambuco bien organizao (sic) porque, sin bordón, canta uno pero sale [...]"48.

Resulta sumamente ilustrativo entender las alteraciones que suponen en el ámbito musical tradicional afroesmeraldeño las modificaciones acaecidas con la aparición de nuevos escenarios, en cuanto a la ubicación de los intérpretes al interior del conjunto. Tradicionalmente, la marimba actuaba como núcleo central del conjunto, alrededor de la cual se disponían el resto de instrumentos. Las cantadoras se situaban al lado del registro agudo de la misma y los bombos y cununos se ubicaban al lado opuesto, es decir, en el registro grave o bordón, de forma que las cantadoras podían, perfectamente, guiarse por la exposición melódica de la marimba, porque la oían adecuadamente ${ }^{49}$.

Sin embargo, la disposición establecida para muchos escenarios actuales, sobre todo los que emplazan a las agrupaciones en una tarima frente al público, presentan a las cantadoras lejos de la marimba, con la sección de bombos y cununos interponiéndose entre ambos, de manera que estas no alcanzan a escuchar apropiadamente a la marimba, por lo tanto la interactuación entre ambos se difumina. Bajo esta disposición, la sección rítmica genera una barrera sonora que desvirtúa la organicidad y sonoridad tradicional afroesmeraldeña ${ }^{50}$.

\section{Características rítmicas}

Como dijimos, a pesar de que la marimba es un instrumento de percusión, su función en el conjunto musical es de carácter melódico y polifónico, por las particularidades mismas del instrumento. Sin embargo, la disposición rítmica del bordón y del tiple contribuyen a la creación del

\footnotetext{
48 Entrevista realizada por Fernando Palacios a Genaro Torres, Guapi (Colombia), 2013.

${ }^{49}$ El marimbista afroesmeraldeño Remberto Escobar detalla, refiriéndose a la posición que deben tomar los instrumentistas en el conjunto de marimba, que "el bombo y los cununos deben colocarse en la parte del bordón o grave de la marimba, y las cantaoras en la parte aguda de la misma. La base melódica se establece así por las cantadoras y el tiple de la marimba". R. Escobar Quiñónez: Memoria viva..., pp. 56, 67.

${ }^{50}$ El marimbista colombiano Héctor Tascón, fue quien nos hizo caer en cuenta de la presente observación. Entrevista realizada por Fernando Palacios a Héctor Tascón, Cali, Colombia, 2014.
} 
fenómeno polirrítmico musical afroesmeraldeño en la interacción con el bombo, los cununos y el guasá.

Veamos dos ejemplos rítmicos de un fragmento musical de marimba, en el bordón y en el tiple, y cómo la unión de ambos establece una nueva idea rítmica:

Allegro

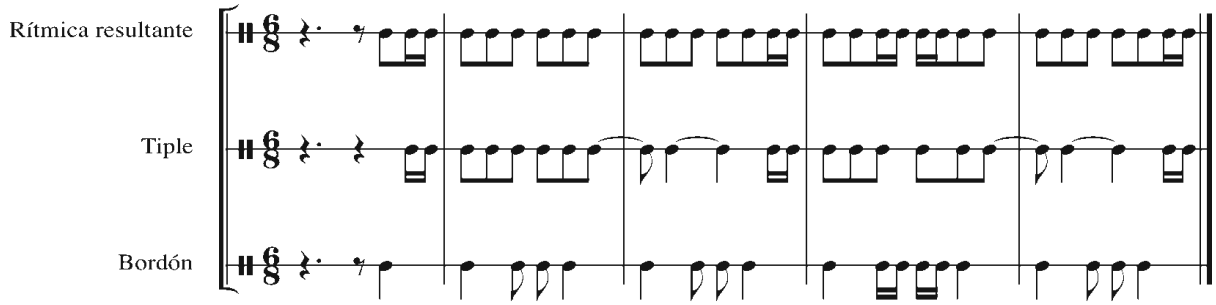

Allegro $\downarrow=120$

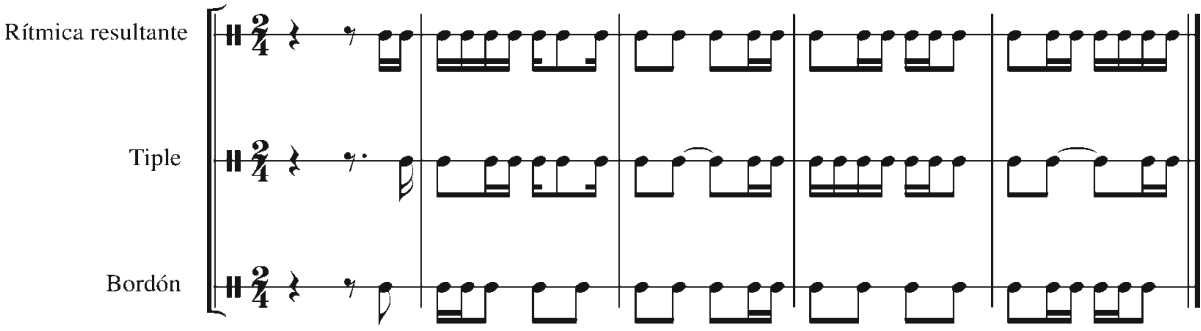

Ejemplo 2. Polirritmia marimba

\section{Características melódicas}

Los registros del instrumento -el grave o bordón y el agudo, tiple o requinta-, determinan sus aspectos melódicos. El bordón establece un bajo de manera repetitiva (ostinato) que sustenta la melodía principal y sus variantes, determinadas por el tiple ${ }^{51}$. Además, el bordonero inicia la parte musical de la marimba, aunque acordando previamente con el tiplero un mismo ámbito sonoro. Cada pieza musical presenta un bordón y un tiple concretos $^{52}$; este último es igual al que realiza la voz para el canto; de hecho,

${ }^{51}$ Luis Felipe Ramón y Rivera: "Música afroecuatoriana", Opus, Revista de la musicoteca del Banco Central del Ecuador, 36, 1989, pp. 36-53.

52 En algunas culturas africanas las funciones de bordón y requinta la realizan dos xilófonos por separado, como entre los Basongye de Zaire donde, según el etnomusicólogo Alan. P. Merriam "se interpretan dos instrumentos afinados en distintas alturas. El más grave interpreta uno de los cuatro patrones que existen, mientras que el agudo interpreta el canto”. A. P. Merriam: The Anthropology..., p. 120. Es 
los marimbistas coinciden en que el instrumento debe cantar como las voces $^{53}$, siendo las variantes realizadas sobre la base melódica en el tiple las que modifican el patrón melódico.

El ámbito melódico es de carácter reducido, tanto en el bordón como en el tiple, no superando, generalmente, la octava. La disposición interválica suele establecerse bajo una estructura pentáfona en algunos casos y heptáfona en otros, no divididas tonométricamente o temperadas en sus distancias ${ }^{54}$.

Las características anteriormente descritas las podemos observar en las siguientes transcripciones:
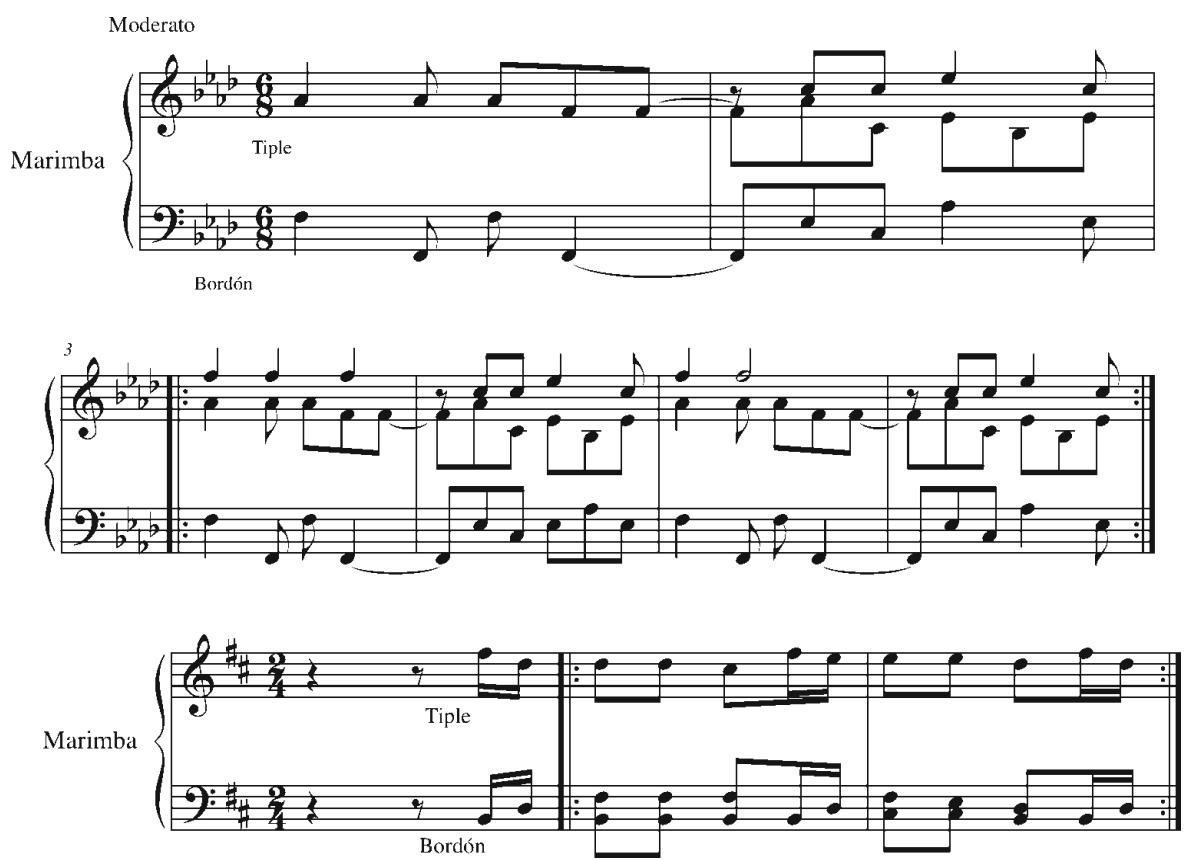

Ejemplo 3. Características melódicas de la marimba

decir, lo que en la marimba afroesmeraldeña, aunque con mayor número de bordones, se interpreta en un solo instrumento, divididos en dos regiones sonoras.

53 El constructor e intérprete afrocolombiano Pacho Torres (2013), expresa: "Se toca lo que se canta. El instrumento tiene que hablar".

${ }^{54}$ Respecto a la relatividad de la importancia atribuida a intervalos determinados en alturas fijas, Merriam establece que en las culturas africanas: "mientras que cada músico reconoce que tercera mayor y una tercera menor no suenan igual, el interprete de xilófono puede ejecutar una u otra en cualquier momento en que una tercera es requerida en la pieza [...]. Así, lo importante es el significado musical, por encima de absolutas diferencias entre dos intervalos". A. P. Merriam: The anthropology..., p. 121. Lo mismo ocurre en la tradición musical afroesmeraldeña. 
El marimbista afroesmeraldeño Remberto Escobar comenta que, en ocasiones, durante el baile de marimba, se establecen unos llamados desafios musicales en la marimba, consistentes en que, insinuando un duelo musical, los intérpretes del bordón y la requinta se retan ${ }^{55}$ :

En las subidas y bajadas en escala, el músico que no se para duro puede ser sacado de la marimba por el otro, en donde se dice que perdió el contrapunto; se van picando las tablas como una forma de desafio, al igual que en los versos que cantan, terminando en un cerrado contrapunteo, en donde la meta de los músicos es desplazar de la marimba a su compañero.

\section{Características polifónicas}

La polifonía característica de la música tradicional afroesmeraldeña se presenta en la marimba mediante la interacción del bordón con el tiple, y en el conjunto, en su relación con las voces para el canto.

Vemos en el siguiente ejemplo algunos de los resultados polifónicos posibles en el transcurso del discurso musical tradicional afroesmeraldeño:

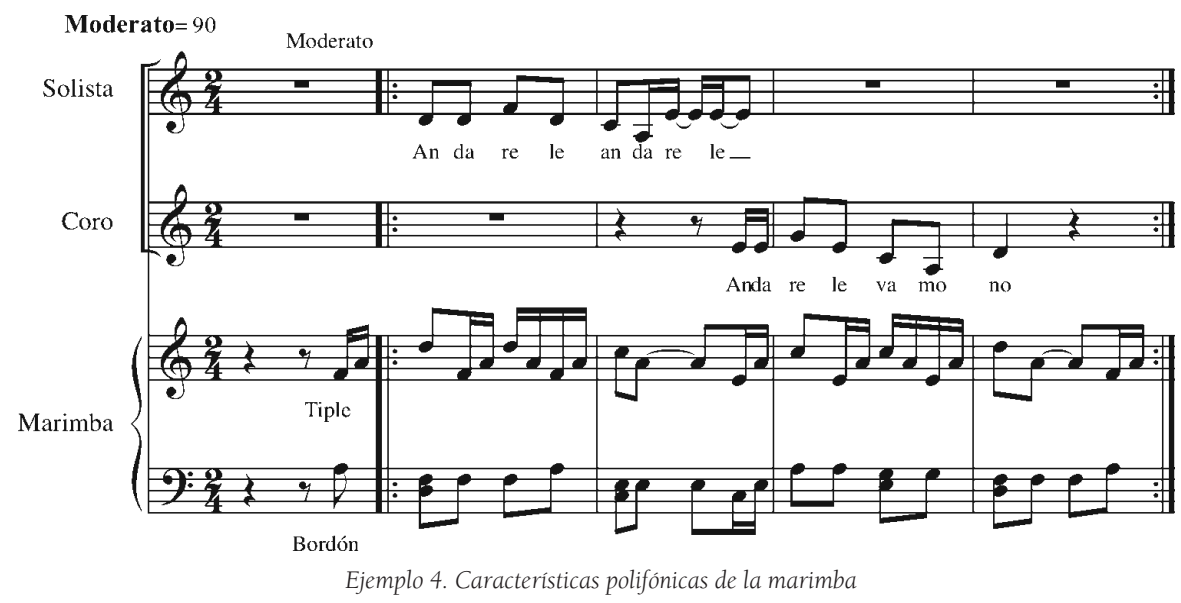

La marimba, como decimos, adquiere una versatilidad extraordinaria en el conjunto instrumental afroesmeraldeño debido a las facilidades melódicas y polifónicas que presenta y a los aportes rítmicos y tímbricos, determinantes para el conjunto.

El entorno geográfico en el que se ha desarrollado la marimba, los grandes ríos de la costa norte pacífica latinoamericana, han constituido, durante siglos, el ámbito sonoro perfecto para su interpretación. De hecho, la

${ }^{55}$ R. Escobar Quiñónez: Memoria viva..., p. 52. 
superficie lisa del río, que muestra tan solo una mínima parte de su interior, se relaciona, intrínsecamente, con la superficie de la marimba, también llana y mostrando la puerta hacia un universo sonoro en el que se puede sumergir el oyente en el momento en que los intérpretes les den vida.
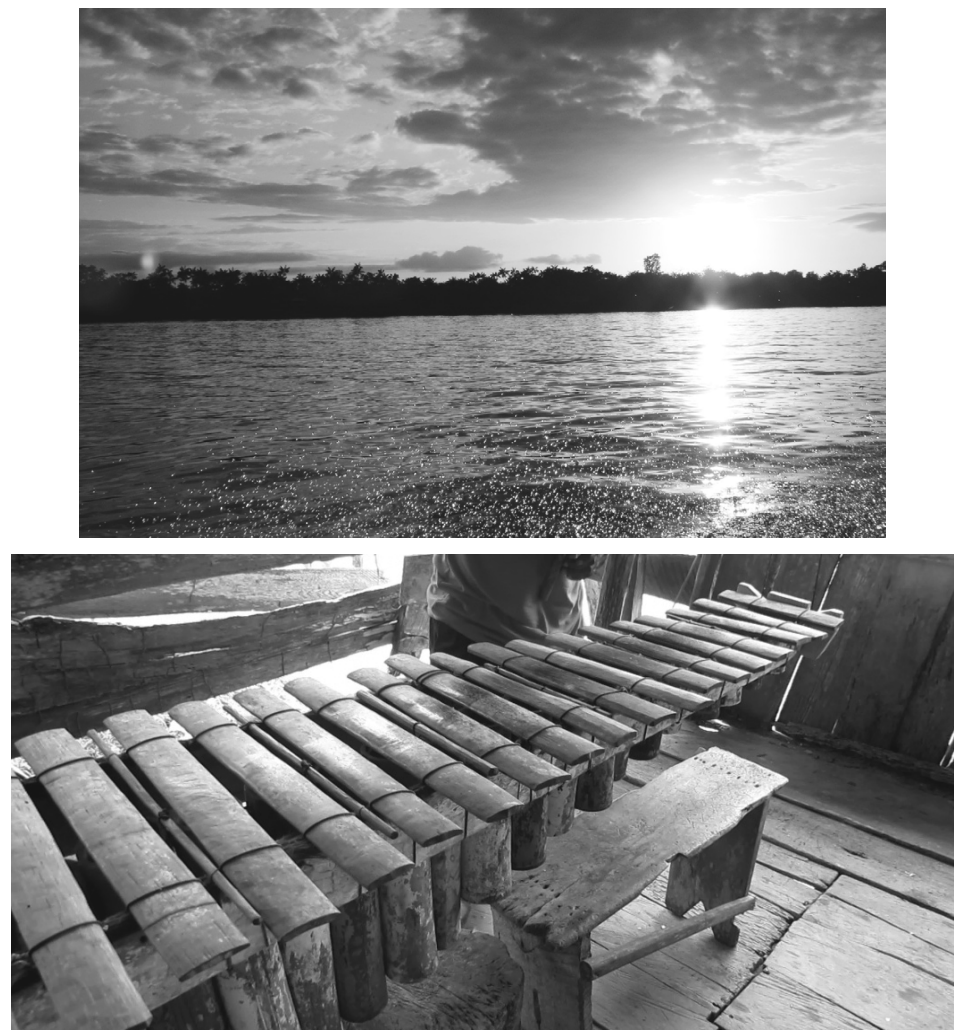

Ilustración 26. Superficies río y marimba

Lamentablemente, la sonoridad tradicional de la marimba, con su disposición interválica no temperada y su timbre cálido y de mediado volumen, no tienen, actualmente, mucha cabida en los entornos geográficos de expresión que le eran naturales, debido, en gran parte, a la pugna auditiva establecida con los reproductores musicales electrónicos, que adquieren un volumen tal, que opaca el entorno sonoro. Sin embargo, siguen determinándose algunos espacios interpretativos que, como bastiones de la tradición, vigencian tanto la sonoridad como la expresión temática genuina de la música afroesmeraldeña; tal es el caso de la parroquia de Telembí, ubicada en la ribera del río Cayapas, al norte de la provincia de Esmeraldas donde, invariablemente la tradición musical se mantiene en uso y es respetada por la comunidad. 
La marimba tradicional afroesmeraldeña se encuentra presente, con similares características formales, en tres grupos culturales ecuatorianos distintos al afroesmeraldeño: los Chachis, los Tsáchilas y los Awa. A pesar de que, con bastante probabilidad, la incorporan desde la tradición afroesmeraldeña, sin embargo, las disposiciones rítmico-melódicas y polifónicas son genuinas en cada uno de sus repertorios.

Cada instrumento musical tradicional afroesmeraldeño aporta al conjunto no solo las disposiciones rítmicas, melódicas, o polifónicas determinadas, sino la tímbrica necesaria para que la sonoridad que le es característica se instituya como genuina y peculiar. Además, los instrumentos musicales permiten rastrear un proceso socio-histórico determinado que aporta datos fundamentales en la comprensión de la actual población afroesmeraldeña y reflejan la estrecha relación que ésta, en la tradición, mantiene con su hábitat. Esta relación se genera a través no solo de los materiales naturales que se emplean para su construcción -los cuales son el resultado de una búsqueda profunda generacional para determinar sus características idóneas para la construcción e interpretación- sino, y fundamentalmente, mediante la sonoridad característica del conjunto instrumental, que se amolda, como si surgiese de las riberas mismas del río o de las costas del océano, al entorno geográfico en el que se originan.

También los instrumentos tradicionales mantienen una carga simbólica significativa tanto en el ámbito festivo como en el religioso, estableciendo el medio necesario para la integración social de la comunidad y abriendo las puertas de comunicación entre la cosmovisión tradicional y las vivencias cotidianas de la población afroesmeraldeña.

Los instrumentos musicales son los que materializan el universo sonoro tradicional; expresan la intangibilidad de la música al ser interpretados y, cuando cesa su ejecución, vuelve la música al misterioso reino de lo impalpable, como la superficie de los ríos o del mar esconde sus secretos bajo las aguas. La voz para el canto y la recitación, la marimba, el bombo, los cununos, el guasá y las maracas son parte integral de la cultura afroesmeraldeña; una cultura de un dinamismo esencial incesante que late al ritmo del corazón del bombo, prodigando vida en cada interpretación. 